\title{
Evaporation Behaviour of a Thinning Liquid Film in a Spin Coating Setup: Comparison Between Calculation and Experiment
}

\author{
José Angél Danglad-Floresa ${ }^{1}$, Stephan Eickelmann ${ }^{1}$, and Hans Riegler ${ }^{1}$ \\ ${ }^{1}$ Max-Planck-Institut für Kolloid- und Grenzflächenforschung
}

July 3, 2020

\begin{abstract}
We present comprehensive measurements of the evaporation behaviour, E, of a thinning film during a hydrodynamic-evaporative spincoating experiment. E, $\omega$ (rotational speed), and $\backslash n u$ (viscosity) are the main control parameters of the process. The evolution of the entire film thinning process can be described theoretically quite well based on the bulk value of $\backslash$ nu of the deposited liquid and with a process-specific (constant) E. The weighing in values of $\backslash$ nu are easily accessible (calculations, literature values, simple measurements). $\mathrm{E}$ is specific for the experimental conditions and values cannot be found in literature. There is also no generally accepted strategy to calculate $\mathrm{E}$ in advance. We analyzed our experimental results in view of a theoretical prediction for $\mathrm{E}$, which was presented already some time ago by Bornside, Macosco, and Scriven, but never tested experimentally. We find good agreement between theory and experiment for many solvents and different! Accordingly, this approach permits in advance the calculation of the evolution of the entire hydrodynamic-evaporative film thinning in a spincoating process. In addition, we present a general formula, which allows in the case of spincoating mixtures of volatile solvents and nonvolatile solutes the prediction of the final solute deposit based on literature data only.
\end{abstract}

\section{Hosted file}

ER-Manu200703-HR.pdf available at https://authorea.com/users/339568/articles/465732evaporation-behaviour-of-a-thinning-liquid-film-in-a-spin-coating-setup-comparisonbetween-calculation-and-experiment 